\title{
Interactive comment on "Hydrology and runoff routing of glacierized drainage basins in the Kongsfjord area, northwest Svalbard" by Ankit Pramanik et al.
}

\section{Anonymous Referee \#2}

Received and published: 29 October 2020

This study examines the hydrology and subsequent freshwater discharge of the glaciers of Kongsfjord, Svalbard. Results of a previous modelling study (same first author) of surface melt and runoff are used as input for a simple and a more complicated routing model, and discharge hydrographs for each outlet are produced.

Overall I found the figures of this paper to be clear and well presented, and the explanations of the previously published methods utilized here to be well explained, but the explanations of the new science done here and the conclusions drawn require significant work before I could recommend this paper for publication. Although the hydrograph outputs are of interest to the field, it was not clear to me exactly what question 
the authors were trying to answer with this study.

Section 5.2 is the key area that is currently lacking in clarity. The choices of these parameter values determine the main output of the study, but I did not find clear justification for the choices made. Furthermore, the choice of why the HydroFlow model is used here seems unclear.

Line by line comments:

Line 10: Is the fact that larger glaciers produce more runoff than smaller ones really a key finding to include in the abstract? Was this not known before the study? Or was it influenced by the water piracy?

Line 18: Are there no supraglacial channels here?

Line 42: Leeson et al 2012 for supraglacial routing (if appropriate here)

Line 47: Capitalized "Water"

Line 60: Is the Pramanik 2019 study relevant here?

Line 63-4: The wording here is confusing. Is there sea ice now? Can you be more specific with exact dates the sea ice was not present.

Line 94: You mention 2010-2016 but the work presented here mainly starts at 2013 ?

Line 98-100: (and similarly in the Appendix) Why was the resampled grid so low resolution? When you had such a high resolution DEM did you not test your simulations with much higher surface resolutions? What was the justification for making the resampled grid so coarse?

Line 139: Can the grid cells that don't receive any flow still produce in-situ melt (that may then travel outside of the boundary)?

Line 144: If the hydraulic potential is so sensitive to this why not try lower DEM resolutions?

Printer-friendly version

Discussion paper 
Line 146: Can you quantify the results of the Monte Carlo simulations here? The description in the appendix seems subjective.

Line 152: What do you mean by "distance" here? The distance from production to discharge? Or between grid cells? I'm also a bit confused what you mean by water wave speed, is this the same as flow speed? At some points you just refer to "water speed" later on in the text, is this the same thing?

Line 159: What is the justification for a uniform speed? Will this not be significantly affected by channel size, presence of firn, etc?

Line 162: How did you determine that this speed was optimal? This seems quite key to not justify in more detail.

Line 173: Can you define the Nash-Sutcliffe coefficient and give a brief explanation of how it is used. This will likely be unfamiliar to many readers.

Line 191: What is the justification for the choice of using HydroFlow here? If subglacial hydrology is important was this model really the right choice if you're having to use similar calibrations to the simple model? It's unsurprising in this case that the results don't differ so much.

Line 227: "Visual inspection" doesn't suggest to me that this key choice has been made rigorously.

Line 235-263: I don't follow your use of “therefore" here. I can't see justification for the choice of $\mathrm{k}=0.8$.

Line 250: The reader needs knowledge of NSC to understand these numbers- why do they show good agreement?

Line 279: Can you elaborate on how the simulations and data support this, or we just have to take your word for it.

Line 282: How do the DEM resolutions compare between the studies? 
Line 317: Have you tried your simulations at a sub-hourly timescale? (If not, why not?) Line 324-326: Can you elaborate on exactly how your conclusions will affect this?

Line 380: How was the choice of cut-off made?

Line 383: Can you use a number instead of "good" which is subjective.

Figure 4: The grey here is hard to see.

Interactive

comment

Interactive comment on The Cryosphere Discuss., https://doi.org/10.5194/tc-2020-197, 2020. 